\title{
Indonesian Language Transfer of Students of English as a Second Language (ESL)
}

\section{Sidupa}

Post Graduate Student of Linguistic Doctoral Program, Faculty of Humanities, University of Indonesia, Depok 16424, West Java, Indonesia

\section{Abstract}

This study examined the issue of transfer for English as a Second Language (ESL) students at the elementary level. The kinds of errors made by 140 students were classified and presented. By using qualitative analysis, the data showed that the errors could be classified into nine parts. These covered the use of the root or simple present form, -ed overgeneralization, spoken target-like form, to "be" omission, "did" overgeneralization, the use of "be" and the simple past or the "ing" form, blended

Corresponding Author:

C. Sidupa

sidupa.christiana@gmail.com

Received: 6 April 2018

Accepted: 3 May 2018

Published: 26 July 2018

Publishing services provided by

Knowledge E

(c) C. Sidupa. This article is distributed under the terms of the Creative Commons

Attribution License, which

permits unrestricted use and redistribution provided that the original author and source are credited.

Selection and Peer-review under the responsibility of the ISLLE 2017 Conference Committee.

\section{G OPEN ACCESS} forms, misselection, and irregular simple past overgeneralization. However, the data showed that in the use of blended forms learners tend to use the irregular simple past and an "s" ending for third-person singular subjects in the simple present. Moreover, learners tend to avoid using the verb "to be" in the simple past. Therefore, the main result indicated that negative transfer or interference happened at a syntactic level, particularly in the use of the simple past tense, from Indonesian as a first language (L1) to English as a second language (L2). In conclusion, in second language acquisition (SLA), interference occurred at sentence level produced by elementary students, especially in the use of the simple past tense. Eventually transfer in the use of the simple past tense was seen as a learning strategy in acquiring English.

Keywords: first language, second language, second language acquisition (SLA), transfer

\section{Introduction}

When two languages interact and influence each other, a languages-in-contact situation exists [1]. The degree to which contact with one language influences performance in another language, of course, connects with the structure of the particular languages that are in contact with each other. Speakers are likely to use their knowledge of one language to generate utterances in another language when the languages share structures that are superficially similar $[2,3]$. 
In the field of SLA, transfer plays an essential role. The role of the $\mathrm{L}_{1}$ to be crucial [4]. The author points out that:

"... individuals tend to transfer the forms and meanings, and the distribution of forms and meanings of their native language and culture to the foreign language and culture - both productively when attempting to speak the language and to act in the culture, and receptively when attempting to grasp and understand the language and the culture as practiced by natives".

In learners' mind, while they are in the second language learning, both the knowledge of their mother tongue and the second language exist at the same time that leads to distinctive linguistic consequences. Refers to this as multicompetence, in this approach, studying transfer becomes a priority because it provides the key evidence that learners process language differently [2008]. Contact between the languages leads to unique, hybrid features that appear in neither of the two source languages, Bahasa Indonesia as the mother tongue and English as the second language.

Two languages are the focus of the research. The mother tongue refers to the first language that human beings have mastered since the beginning of their life through interaction with their fellow members of the language community, especially with their family, whereas a second language refers to any language learnt other than the mother tongue [6].

Currently English, at the forefront of international relations, business, tourism, education, science, technology, computers, and the media [7]. English, therefore, has been considered to play a significant role in developing and changing a country's economic system. In addition, based on the English user circle model, Indonesia is in an expanding circle whose population learns English [8]. Consequently, English has become a compulsory subject from secondary school until adult education in Indonesia.

As previously mentioned, people rely on their first language when they learn the target language has been recently confirmed in an empirical study carried out by Jarvis and Pavle $[4,9]$. In particular, they argue that transfer or cross-linguistic influence refers to the influence of one language on another in an individual's mind. They also present interesting findings and an analysis of the relationship between language transfer and second language acquisition (SLA). Based on their findings, the study will investigate the role of $\mathrm{L}_{1}$ in the acquisition of the simple past tense in the context of Indonesian learners of English. 


\section{Methods}

This section discusses the subjects of the study, the research question, and the methods used in the analysis of the written texts.

\subsection{The subjects of the study}

Based on the results of a formative assessment, five classes were selected from grade 6. The target location was a private elementary school. Each group consisted of 28 Indonesian learners of English, aged between 11 and 12, with elementary- English. The subjects were all Indonesian speakers and had been learning English as a second language, attending four sessions per month on average. One of the aims of the current study is to investigate the cross-linguistic influence of L1 (Indonesian language) in acquiring linguistic items of L2 (English).

\subsection{Questionnaire}

The current study seeks to answer the following question: How do learners transfer $L_{1}$ to the acquisition of $L_{2}$ (English) linguistic items, particularly the simple past tense? This is to provide evidence in relation to the acquisition of simple past tense forms to prove Mourssi's theory about seven categories in acquiring the simple past in English $[10,11]$.

\subsection{Methods}

To answer the research question presented above, qualitative analyses were conducted for all the simple past tense forms produced by 140 writing tests at a single point in time. Therefore, a cross-sectional study of interlanguage influence is conducted. In order to explore interlanguage phenomena and the influence of L1 in acquiring linguistic items, in this case the simple past tense, the author categorizes the errors made by the participants. The results are presented in the following section.

\section{Results}

From a total of 140 students' writing tests, their simple past tense errors can be categorized into several parts. 
1. Use of the root or simple present form

You call me yesterday.

He goes to school this morning.

Are we at home last night?

After he has breakfast, he went to school this morning.

2. Overgeneralizing the -ed with regular or irregular verbs

We studyed math and English last night.

They taked a bath at 6 this morning.

She readed some comic books.

They sleeped yesterday.

I writed some notes yesterday.

He hasded breakfast this morning.

After school we plaied together yesterday.

We doed the homework at 7 p.m. yesterday.

3. Use of spoken target-like form but in a written nontarget-like form

We stadid math and English yesterday.

After school we pleid together yesterday.

She wok up at 5 this morning.

They slapt at 9 p.m. last night.

She red some comic books.

4. Omission of the verb to "be" ("were")

We $\varnothing$ at home last night.

5. Overgeneralizing the use of "did" for interrogative sentences

Did we at home last night?

Did we were at home last night?

Did Dimas stopped watching cartoons in 2010?

6. Use of verb to "be" + simple past or "-ing" form

You were called me yesterday.

Jessica was playing with dolls in 2009. 
7. Use of blended form (use of irregular simple past + an " $s$ " ending for third person singular subjects in simple present)

She wokes up at 5 this morning.

He wents to school yesterday.

8. Misselection of the target-like verb form

Dimas were in Bali last year.

We was at home last night.

9. Overgeneralizing a subrule of one irregular simple past on another irregular simple past

She toke a bath at 6 .

She woke up at 5.

The analysis of the simple past forms produced by the learners appears to indicate that the Indonesian language has an influence in the acquisition of the English simple past as described in the previous section. The study shows overgeneralization of newly encountered rules. Here, the learners overgeneralize L2 structure in forming another linguistic item.

Of course, in acquiring the simple past there are seven categories. They are the use of the root or simple present form, overgeneralization of the -ed with regular or irregular verbs, the use of the spoken target-like form but in a written nontarget-like form, the verb to "be" + the simple past or -ing form, blended forms (the use of have, has + the simple past or past participle and the use of the infinitive + the simple past or past participle), misselection of the target-like verb form, and overgeneralization of a subrule of one irregular simple past on another irregular simple past [12]. However, the data show that for the use of the blended form, learners tend to use the irregular simple past + an "s" ending for third person singular subjects in the simple present. In addition, learners have a tendency to omit the verb to "be" in the simple past. Moreover, they prefer to overgeneralize the use of "did" for interrogative sentences.

\section{Conclusion}

To sum up, most of the past tense forms produced by the subjects appear to indicate a cross-linguistic influence of the Indonesian language (L1) in acquiring linguistic items of English (L2) in the context of Indonesian learners of English in elementary school. Transfer as a series of learning strategies that consist in relying on existing knowledge 
to make learning easier [13]. He differentiates one strategy from another. Transfer implies relying on the L1 whereas overgeneralization affects the L2 exclusively. In addition, it cannot be denied that the role of the mother tongue plays an important part in the language learning process. The more distant linguistically from the mother tongue the longer a language takes to learn [14] In conclusion, in acquiring a second language, the more similar the mother tongue and the target language are, the greater the help the mother tongue can give.

\section{References}

[1] Brice AE, Rivero Y: Language Transfer: First (L1) and Second (L2) Proficiency of Bilingual Adolescent Students. The Journal for Language Teaching and Learning, 1996; 12(2): 1-16.

[2] Dopke S: Generation of and Retraction from Cross-Linguistically Motivated Structures in Bilingual First Language Acquisition'. Bilingualism: Language \& Cognition. 2000; 3(3): 209-226.

[3] Tracy R: Child Language in Contact: Bilingual Language Acquisition (English/German) in Early Childhood. Habilitationsschrift: University of Tubingen; 1995.

[4] Lado R: Linguistics Across Cultures. Ann Arbor: University of Michigan Press; 1957.

[5] Cook V: Second Language Learning and Language Teaching. London: Routledge; 2013.

[6] Kridalaksana H: Kamus Linguistik (ed. ke-4). Jakarta: PT Gramedia Pustaka Utama; 2013.

[7] Seawright L: Going Global: Transnational Perspectives on Globalization, Language, and Education. Newcastle: Cambridge Scholars Publishing; 2014.

[8] Kachru Y, Smith LE: Cultures, Context, and World Englishes. New York: Routledge; 2008.

[9] Jarvis S, Pavlenko A: Crosslinguistic Influence in Language and Cognition. New York: Routledge; 2008.

[10] Mourssi A: Analyzing Interlanguage Stages ALEs Pass Through in the Acquisition of the Simple Past Tense. English Language Teaching. 2012; 5(1): 148-163.

[11] Mourssi A: The Acquisition of the Simple Past Tense in the Context of Arab Learners of English. Arab World English Journal. 2012; 3(3): 204-222. 
[12] Mourssi, A: The Role of Revising and Redrafting in Improving Second Language Learners' Writing: The Acquisition of the Simple Past. Dissertation, University of the West of England Bristol UK; 2013.

[13] Villanueva LC: The Role of the $L_{1}$ in the Acquisition and Use of the L2: New Perspectives. Barcelona English Language and Literature Studies. 1990; 2: 73-79.

[14] Gass SM, Selinker L: Language Transfer in Language Learning. Amsterdam: John Benjamins Publishing Company; 1992. 